\title{
A formação de educadores do ProJovem Campo - Saberes da Terra e o ensino de conteúdos estatísticos
}

\author{
Luciana Rufino de Alcântara \\ Programa de Pós-Graduação em Educação Matemática e Tecnológica - Edumatec/UFPE \\ lucianaralcantara@gmail.com
}

\section{Carlos Eduardo Ferreira Monteiro}

Programa de Pós-Graduação em Educação Matemática e Tecnológica - Edumatec/UFPE Centro de Educação, Universidade Federal de Pernambuco.

cefmonteiro@gmail.com

\section{Iranete Maria da Silva Lima}

Programa de Pós-Graduação em Educação Matemática e Tecnológica - Edumatec/UFPE Centro de Acadêmico do Agreste, Universidade Federal de Pernambuco.

iranetelima@yahoo.com.br

\section{Resumo}

A Educação do Campo possui instrumentos pedagógicos para melhor atender a população que historicamente tem tido desvantagens no processo de escolarização. Um desses instrumentos é a Integração de Saberes entre as áreas do conhecimento e as realidades camponesas. O Programa ProJovem Campo - Saberes da Terra- foi concebido a partir dessa abordagem. Neste artigo trazemos um recorte de uma pesquisa que investigou a formação de educadores no referido Programa em Pernambuco, enfocando, em particular, o perfil de formação e profissional dos educadores que atuavam nas áreas de Ciências da Natureza e Matemática, bem como alguns aspectos da formação sobre o ensino de conteúdos estatísticos. Os dados foram coletados a partir de questionários e analisados com base em categorias que emergiram das respostas dos participantes. A pesquisa forneceu elementos para o debate sobre o ensino de Estatística em Escolas do Campo.

Palavras-chave: Ensino de Estatística. ProJovem Campo - Saberes da Terra. Integração de Saberes. Educação do Campo. Formação de Educadores.

\section{The teacher education of ProJovem Campo - Land Knowledge educators of and teaching of statistics contents}

\begin{abstract}
The Field Education has pedagogical tools to better support the population of field that historically has had disadvantages in the schooling process. One of these tools is the integration of knowledge, which includes the relationship between different knowledge areas with field population. The ProJovem Field Program - Land Knowledge - is based on that integrative approach. This article discusses part of a research that investigated the teacher education involved in that program in the state of Pernambuco. Therefore, this article aims to analyse the profile of educators in the area of Natural Sciences and Mathematics, as well aspects of their teacher education related to the teaching
\end{abstract}


of statistics. The research data were collected from questionnaires and the data analysis were based on the categories that emerged from the participants' responses. The study provided elements to the debate over the teaching of statistics in context of field education.

Keywords: Statistics Teaching. ProJovem Field - Land Knowledge. Integration of Knowledge. Field Education. Teacher Education.

\section{Introdução}

No Brasil, por um longo período histórico, que se estende até os dias atuais, as populações que vivem no Campo não têm pleno acesso à educação escolar. As condições precárias de muitas escolas localizadas em áreas rurais são indícios importantes dessa realidade.

Contrapondo-se a esse cenário e à concepção a ele subjacente nasce e se fortalece a Educação do Campo. Adotando os pressupostos da Educação Popular (FREIRE, 1996) tem como premissa a valorização dos conhecimentos dos sujeitos do Campo no processo educativo.

Caldart (2012, p.257) conceitua a Educação do Campo da seguinte maneira:

Educação do Campo nomeia um fenômeno da realidade brasileira atual, protagonizada pelos trabalhadores do campo e suas organizações, que visa incidir sobre a política de educação desde os interesses sociais das comunidades camponesas. Objetivo e sujeitos a remetem às questões do trabalho, da cultura, do conhecimento e das lutas sociais dos camponeses e ao embate (de classe) entre projetos de campo e entre lógicas de agricultura que têm implicações no projeto de país e de sociedade e nas concepções de política pública, de educação e formação humana.

Como se pode observar, a Educação do Campo é um projeto de sociedade que ultrapassa os muros da escola. Todavia, a ideia é complexa uma vez que as realidades camponesas são múltiplas, assim como seus atores e interlocutores.

Para muitos educadores ${ }^{1}$ que atuam em escolas situadas em áreas rurais, o campo é concebido como um lugar de carências e falta de possibilidades (MONTEIRO; LEITÃO; ASSEKER, 2009). Nesse cenário, o campo é entendido como não-lugar, de ausência de bens e serviços que existem na cidade; o rural é a negação da cidade (WANDERLEY, 2001). A Educação do Campo não se insere na perspectiva do urbano centrismo tampouco do ruralismo. Ela preconiza as inter-relações entre o urbano e o rural, entre o campo e a cidade, entre o universal e o local. Ela nasce em um espaço de contradição e de disputa pela terra e pelo direito a educação, dentre outras lutas protagonizadas pelos povos do Campo. Por um lado tem-se o êxodo rural, o crescimento do agronegócio, o alto índice de analfabetismo e o analfabetismo funcional. Por outro, há elementos

\footnotetext{
${ }^{1}$ Mesmo considerando e valorizando a importância atribuída à diferenciação de gênero, neste artigo, para simplificar a leitura, utilizamos apenas as palavras educando, educador, professor e aluno. As palavras professor e educador, bem como educando, aluno e estudante são empregados no texto, respectivamente, como sinônimos.
} 
propositivos de transformação, a exemplo das reivindicações e lutas pelo direito à terra e do fortalecimento da agricultura familiar camponesa (MUNARIM, 2011).

Nas últimas décadas, diversas universidades brasileiras se engajaram em ações conjuntas com os Movimentos Sociais do Campo visando compreender e contribuir com/para a consolidação da Educação do Campo. Nesse contexto, a Universidade Federal de Pernambuco (UFPE) aderiu ao Programa ProJovem Campo - Saberes da Terra (BRASIL, 2008a), em consonância com os objetivos do projeto de expansão e de interiorização das universidades públicas federais no Brasil. Professores e estudantes da UFPE, em parceria com representantes de outras instituições que atuam no Campo e dos Movimentos Sociais, buscaram contribuir com a elevação da escolaridade de pessoas jovens e adultas, cuja faixa etária não é atendida pelo ensino regular, por meio da realização da formação dos educadores. Esta ação de formação continuada resultou, também, na realização de pesquisas acadêmicas.

Apresentamos, portanto, um recorte de uma pesquisa que investigou a formação dos educadores do ProJovem Campo $^{2}$ que ensinavam Ciências da Natureza e Matemática (ALCÂNTARA, 2012). O estudo considerou os instrumentos pedagógicos proposto pelo Programa, como a Integração dos Saberes entre os conhecimentos escolares estudados nos anos finais do Ensino Fundamental e os saberes da realidade camponesa. Neste artigo, apresentamos, em particular, o perfil de formação e profissional dos educadores do Programa em Pernambuco e alguns elementos sobre a formação inicial e continuada desses educadores com relação aos conteúdos estatísticos que devem ser ensinados nos anos finais do Ensino Fundamental, nível escolar atendido pelo Programa.

Nas seções que seguem, abordamos o paradigma da Educação do Campo e alguns aspectos do ProJovem Campo, enquanto programa do governo federal, e o método adotado no estudo. Após apresentarmos elementos da análise dos dados, tecemos algumas considerações conclusivas que podem contribuir para subsidiar o ensino de Matemática, em particular, de conteúdos estatísticos em contextos educacionais do Campo.

\section{O ProJovem Campo e o ensino de conteúdos estatísticos}

O ProJovem Campo teve como objetivo oportunizar aos jovens agricultores familiares, excluídos do sistema regular de ensino (BRASIL, 2008b), o acesso à escolarização e à qualificação social e profissional. Para tanto, ofereceu os anos finais do Ensino Fundamental na modalidade de Educação de Jovens e Adultos (EJA).

O Programa adotou a Alternância Pedagógica (GIMONET, 2007) como metodologia de ensino. Essa metodologia caracteriza-se, de uma parte, pela organização do tempo escolar que

\footnotetext{
${ }^{2}$ Doravante utilizamos a expressão ProJovem Campo como referência ao Programa ProJovem Campo - Saberes da Terra.
} 
alterna momentos na escola e momentos de formação na família e, de outra, pelo uso de ferramentas pedagógicas como a Integração de Saberes. A sua utilização demanda, portanto, dos educadores um conhecimento mais amplo do processo educativo no Campo, considerando as dimensões sociais, culturais, políticas, ambientais e produtivas.

A organização curricular proposta pelo ProJovem Campo tem como eixo gerador a Agricultura Familiar e a Sustentabilidade, em torno do qual se articulam os seguintes eixos temáticos que dialogam entre si (BRASIL, 2008a, p.38):

- Agricultura Familiar: identidade, cultura, gênero e etnia;

- Sistemas de Produção e Processo de Trabalho no Campo;

- Cidadania, Organização Social e Políticas Públicas;

- Economia Solidária;

- Desenvolvimento sustentável e solidário com enfoque territorial.

O Programa prevê, também, a articulação desses eixos temáticos com as seguintes áreas de conhecimento: Linguagens e Códigos; Ciências da Natureza e Matemática; Ciências Agrárias; e Ciências Humanas.

Na pesquisa nos interessamos, especificamente, pelos educadores que atuaram na Área de Ciências da Natureza e Matemática, uma vez que eles ensinavam os conteúdos estatísticos, objeto matemático escolhido para investigação. A hipótese subjacente a esta escolha é que o trabalho com os conteúdos estatísticos pode favorecer a Integração de Saberes preconizada pelo Programa em foco.

Os PCN (BRASIL, 1997) sugerem que o ensino nos anos finais do Ensino Fundamental deve contemplar os seguintes aspectos:

Coleta, organização de dados e utilização de recursos visuais adequados (fluxogramas, tabelas e gráficos) para sintetizá-los, comunicá-los e permitir a elaboração de conclusões. Leitura e interpretação de dados expressos em tabelas e gráficos. Compreensão do significado da média aritmética como um indicador da tendência de uma pesquisa. (p.74).

Todavia, a compreensão de conceitos e conteúdos estatísticos exige muito mais que o ensino de procedimentos estandardizados, uma vez que eles são necessários para que o cidadão interprete e compreenda diversas situações sociais. Nesse sentido, vários autores da área da Educação Estatística, tais como Carvalho e Solomon (2012), enfatizam que a aprendizagem da Estatística é essencial para uma reflexão crítica e para o exercício da cidadania participativa.

Santos e Magina (2007) discutem a importância que é atribuída nos PCN (BRASIL, 1997) ao ensino de conceitos básicos de Estatística desde os anos iniciais de escolarização. As autoras ressaltam que antes da publicação desse documento os conteúdos estatísticos não faziam parte dos 
currículos dos cursos de formação de professores. Assim, os professores eram desafiados a ensinarem conceitos e conteúdos estatísticos, o que se observa ainda na atualidade. A partir dessa publicação muitas discussões e pesquisas têm sido desenvolvidas no sentido de contribuir com e para o enfrentamento das dificuldades sobre a efetivação do ensino de Matemática e Estatística, nos diversos níveis de escolarização. Por exemplo, tem-se ampliado a discussão sobre os contextos socioculturais como um aspecto relevante para o ensino, sobretudo, no âmbito da Educação do Campo. Em um estudo sobre escolas multisseriadas do Campo em interface com a Educação Matemática, Knijnik e Wanderer (2013) discutem a importância do ensino da Matemática valorizar os saberes locais e a incorporação de práticas matemáticas do contexto social no currículo escolar. Lima (2014) também estuda o ensino de matemática em escolas do campo sobre a lente da Educação Matemática Crítica (SKOVSMOSE, 2001, 2008) que discute o ensino de matemática por meio da problematização e da criticidade.

Para se considerar plenamente alfabetizados em Matemática, os alunos precisam também compreender conteúdos estatísticos para, por exemplo, interpretarem tabelas de dupla entrada, mapas e gráficos. Dados do Indicador de Analfabetismo Funcional (INAF, 2012) indicam que a proporção de analfabetos funcionais nas áreas rurais é de 44\%, enquanto que nas áreas urbanas esse índice é de $24 \%$. Esses são dados que evidenciam a necessidade de acesso, sobretudo dos camponeses, a uma educação de qualidade. Destacamos a relevância da formação estatística do homem e da mulher do Campo, na medida em que por trás de dados estatísticos amplamente difundidos pelos meios de comunicação sobre as populações camponesas estão pessoas, famílias e comunidades, trabalhadores do Campo.

\section{O estudo}

Como anunciamos, os sujeitos da pesquisa foram os educadores que atuavam na área de Ciências da Natureza e Matemática no ProJovem Campo em Pernambuco. Vale ressaltar que eles foram selecionados pela Secretaria de Educação do Estado de Pernambuco para atuarem exclusivamente no Programa. Conjecturando que nem todos os educadores possuíam formação específica nas duas áreas de conhecimento, buscamos identificar o perfil de formação e profissional dos participantes da pesquisa. Com isto objetivamos, também, ter acesso à elementos sobre a formação em Estatística desses educadores.

Propomos, então, um questionário que foi respondido por 132 educadores que participavam no momento da coleta dos dados, outubro de 2010, do módulo do Curso de Aperfeiçoamento em Educação do Campo oferecido pela UFPE. Esse curso, que se configura em formação continuada, teve carga horária de 360 horas e foi realizado em Alternância Pedagógica, 
intercalando períodos na universidade e períodos nas comunidades onde estavam sediadas as escolas do campo nas quais os educadores atuavam (LIMA; FRANCO, 2014).

Os educadores lecionavam em realidades locais diversas, a saber: comunidades de pescadores, indígenas e quilombolas. Ao analisarmos as respostas aos questionários, identificamos 8 educadores que não tinham formação nas áreas de Ciências da Natureza e Matemática, uma vez que haviam sido contratados para exercerem a função de coordenadores de turmas. Optamos por não analisar as respostas desses sujeitos. Assim, consideramos as respostas de 124 educadores que responderam a questões relacionadas aos seguintes aspectos: tempo de experiência na docência; formação acadêmica; perfil dos educandos atendidos nas turmas no ProJovem Campo; identificação dos conteúdos estatísticos trabalhados nos cursos de graduação, contribuição da formação continuada para o ensino da Estatística nas escolas do Campo. Contudo, como já explicitado, neste artigo não abordamos todos esses aspectos.

Os dados obtidos foram organizados e analisados com base em categorias construídas a partir das especificidades do ProJovem Campo e de aproximações entre as respostas dadas pelos professores.

\section{Resultados obtidos e Análise}

Dos 124 respondentes de nossa pesquisa, 94 eram do gênero feminino. Apenas 13 educadores haviam tido uma experiência anterior com o Programa, por meio do projeto piloto que aconteceu nos anos de 2005 e 2006. Portanto, a maioria dos respondentes estava tendo um contato inicial com a proposta da Integração de Saberes e da Metodologia da Alternância pela primeira vez.

Na Tabela 1 são apresentados os dados relacionados à formação inicial dos educadores.

Tabela 1. Formação inicial dos educadores/as

\begin{tabular}{lr}
\hline \multicolumn{1}{c}{ Curso de graduação } & Número de educadores (\%) \\
\hline Licenciatura em Biologia & $59(48 \%)$ \\
Licenciatura em Matemática & $54(43 \%)$ \\
Outras formações (bacharelados) & $11(09 \%)$ \\
\hline Total & $\mathbf{1 2 4}(\mathbf{1 0 0 \% )}$ \\
\hline
\end{tabular}

Fonte: Acervo da Pesquisa.

91\% dos educadores tinham cursado a licenciatura Biologia ou em Matemática, o que é compatível com a área do Programa Ciências da Natureza e Matemática para a qual haviam sido contratados. Os demais $(9 \%)$ eram formados em outras áreas, algumas consideradas afins, a 
exemplo das Ciências Biomédicas. Porém, como se pode observar, menos da metade dos professores tinham formação específica em Matemática.

Buscamos, também, identificar se os professores já tinham cursando ou se estavam cursando uma especialização lato sensu e em que área de conhecimento. Os resultados são apresentados na Tabela 2 .

Tabela 2. Formação lato sensu concluída ou em andamento

\begin{tabular}{l|c|c|c|c|c}
\hline \multirow{2}{*}{$\begin{array}{c}\text { Área da formação } \\
\text { inicial (graduação) }\end{array}$} & \multicolumn{5}{c}{ Área da formação lato sensu } \\
\cline { 2 - 6 } & $\begin{array}{c}\text { Ensino de } \\
\text { Biologia }\end{array}$ & $\begin{array}{c}\text { Ensino de } \\
\text { Matemática }\end{array}$ & Educação & $\begin{array}{c}\text { Outras } \\
\text { áreas }\end{array}$ & $\begin{array}{c}\text { Não } \\
\text { cursaram }\end{array}$ \\
\hline $\begin{array}{l}\text { Licenciatura em } \\
\text { Biologia } \\
\text { Licenciatura em }\end{array}$ & 23 & -- & 17 & 08 & 11 \\
$\begin{array}{l}\text { Matemática } \\
\begin{array}{l}\text { Outras formações } \\
\text { (bacharelado) }\end{array}\end{array}$ & -- & 34 & 09 & -- & 11 \\
\hline Total & -- & -- & -- & 09 & 02 \\
\hline
\end{tabular}

Fonte: Acervo da pesquisa.

Conforme pode ser observado na Tabela 2, apenas 24 educadores não haviam cursado uma especialização lato sensu. Como esperado, a maioria dos licenciados em Matemática buscou uma formação na área de Ensino em Matemática e os licenciados em Biologia nesta mesma área. Esses dados apontam para uma realidade diferente da que foi identificada por outros estudos sobre a formação de professores que ensinam no Campo, como por exemplo, os estudos de Farias (2010) que evidenciam limitações do perfil de formação desses professores.

Buscamos, também, identificar o tempo de experiência que os professores investigados tinham com o ensino na educação básica. Na Tabela 3 apresentamos os resultados obtidos.

Tabela 3. Tempo de experiência com o ensino

\begin{tabular}{lr}
\hline \multicolumn{1}{c}{ Experiência (em anos) } & Número de educadores (\%) \\
\hline 0 a 2 anos & $23(18 \%)$ \\
3 a 5 anos & $14(11 \%)$ \\
Mais de 5 anos & $85(68 \%)$ \\
Não responderam & $02(03 \%)$ \\
\hline Total & $\mathbf{1 2 4}(\mathbf{1 0 0 \% )}$ \\
\hline
\end{tabular}

Fonte: Acervo da pesquisa.

Conforme a Tabela 3 apresenta, 68\% dos educadores tinham mais de cinco anos de experiência com o ensino. Consideramos esse resultado relevante tendo em vista que os educadores já estavam familiarizados com a vivência escolar, mesmo que tivessem atuado em modalidades de ensino e contextos educacionais diferentes daquele atendido pelo ProJovem Campo. 
Buscamos, então, saber se os professores tinham experiência com o ensino de matemática. $35 \%$ (44 professores) responderam que tinham até dois anos de experiência com esse ensino e 55\% (68 professores) que ensinavam matemática há mais de dois anos. Esse resultado é relevante por mostrar que embora apenas 43\% dos professores (Cf. Tabela 1) fossem licenciados em Matemática, a maioria (90\%) já tinha experiência com o ensino nesta área do conhecimento.

Em seguida, perguntamos aos professores se na formação inicial haviam estudado conteúdos estatísticos. As respostas obtidas estão explícitas na Tabela 4:

Tabela 4. Estudaram conteúdos estatísticos na formação inicial?

\begin{tabular}{lr}
\hline \multicolumn{1}{c}{ Resposta } & Número de Educadores (\%) \\
\hline Sim & $93(75 \%)$ \\
Não & $24(19 \%)$ \\
Não responderam & $07(06 \%)$ \\
\hline Total & $\mathbf{1 2 4}(\mathbf{1 0 0 \% )}$ \\
\hline
\end{tabular}

Fonte: Acervo da pesquisa.

Esse resultado indica que a maioria dos professores tinha familiaridade com os conteúdos estatísticos, embora nem todos tivessem formação em Matemática. Buscando complementar esta informação, de maneira mais pontual, perguntamos aos professores se eles lembravam os conteúdos que foram trabalhados nos cursos de graduação. As respostas dos professores estão sintetizadas na Tabela 5.

Tabela 5. Conteúdos estatísticos foram trabalhados na graduação?

\begin{tabular}{lr}
\hline \multicolumn{1}{c}{ Síntese das respostas } & Número de professores (\%) \\
\hline $\begin{array}{l}\text { Os conteúdos estatísticos não foram trabalhados } \\
\text { Citaram conteúdos estatísticos ou formas de } \\
\text { registros estatísticos }\end{array}$ & $24(19 \%)$ \\
$\begin{array}{l}\text { Citaram conteúdos estatísticos e, também, } \\
\text { conteúdos de outros campos da Matemática }\end{array}$ & $43(35 \%)$ \\
$\begin{array}{l}\text { Citaram conteúdos de outros campos da } \\
\text { Matemática (conteúdos não estatísticos) } \\
\text { Não responderam }\end{array}$ & $11(09 \%)$ \\
\hline Total & $06(05 \%)$ \\
\hline
\end{tabular}

Fonte: Acervo da pesquisa

Apenas 35\% dos professores citaram conteúdos estatísticos ou formas de registros estatísticos. Dentre eles: média, mediana, moda, gráficos, tabelas e medidas de tendência central. Nossa expectativa era que esse percentual fosse maior, tendo em vista que $75 \%$ dos professores 
declararam ter estudado conteúdos estatísticos nos cursos de graduação (Cf. Tabela 4). Constatamos, porém, que a maioria não tinha clareza dos conteúdos que foram trabalhados nesse campo. $17 \%$ dos professores confundiram parcial ou totalmente conteúdos estatísticos com conteúdos de outros campos da Matemática. Observa-se, também, que o total de professores que alegaram não ter estudado tais conteúdos e os que não responderam a questão corresponde a 51\% dos professores.

Uma explicação para esse resultado pode ser atribuída ao tempo decorrido após a formação inicial. Vale destacar, porém, que o módulo (tempo universidade) do curso de aperfeiçoamento em que os conteúdos estatísticos foram trabalhados com os professores foi vivenciado antes da aplicação do questionário da pesquisa. Naquele módulo foram trabalhados problemas, dentre outros, de interpretação de gráficos e tabelas, além de ter sido ressaltada a relevância do ensino da Estatística na educação básica. Assim, o fato de não citarem ou não distinguirem um conteúdo estatístico pode indicar eventuais dificuldades que eles enfrentam no processo de ensino, mesmo que alguns professores tenham estudado tais conteúdos, tanto na formação inicial quanto na continuada. Entretanto, faz-se necessário investigar de maneira mais aprofundada o que veio a influenciar tais respostas e possíveis consequências na atividade do professor em sala de aula.

Com o intuito de complementar as informações obtidas nas respostas das questões precedentes, perguntamos aos professores: Como você avalia o ensino dos conteúdos de Estatística trabalhados na graduação? As respostas estão apresentadas na Tabela 6.

Tabela 6. Avaliação sobre o ensino de conteúdos de Estatística na graduação

\begin{tabular}{lr}
\hline \multicolumn{1}{c}{ Respostas } & Número de Professores (\%) \\
\hline Foram pouco trabalhados & $56(45 \%)$ \\
Trabalhou-se o necessário & $31(25 \%)$ \\
Trabalhou-se bem & $14(11 \%)$ \\
Não responderam & $23(19 \%)$ \\
\hline Total & $\mathbf{1 2 4}(\mathbf{1 0 0 \% )}$ \\
\hline
\end{tabular}

Fonte: Acervo da pesquisa.

Apenas $11 \%$ dos educadores avaliaram que os conteúdos estatísticos foram bem trabalhados nos cursos de graduação. Para 25\% dos professores os conteúdos foram trabalhados o necessário e uma quantidade expressiva (45\%) alegou que tais conteúdos foram pouco trabalhados. Nota-se que os 19\% que não responderam a questão são os mesmos professores que já haviam alegado não ter estudado Estatística na formação inicial (Cf. Tabela 4).

Como se pode observar na Tabela 6, o percentual de professores que admitiram ter estudado conteúdos estatísticos na graduação passa de $75 \%$ para $81 \%$, embora a maioria considere 
que o estudo não foi satisfatório. Esse resultado pode justificar, ao menos em parte, porque os professores não explicitaram nas suas respostas os conteúdos estatísticos estudados.

Perguntamos aos professores se consideravam que os conceitos básicos para ensinar Estatística aos seus educandos foram aprendidos nas formações. Nosso objetivo foi estabelecer uma relação entre a formação dos professores e o trabalho que realizavam na sala de aula. As respostas dos professores são apresentadas na Tabela 7.

Tabela 7. Os conceitos básicos para ensinar Estatística foram aprendidos nas formações?

\begin{tabular}{lr}
\hline Resposta & Número de Professores (\%) \\
\hline Sim & $70(56 \%)$ \\
Não & $18(15 \%)$ \\
Não responderam & $36(29 \%)$ \\
\hline Total & $\mathbf{1 2 4 ( 1 0 0 \% )}$
\end{tabular}

Fonte: Acervo da pesquisa.

Embora apenas 36\% dos professores tenham afirmado, nas respostas à questão anterior, que na formação inicial os conteúdos estatísticos foram trabalhados suficiente ou satisfatoriamente, $56 \%$ afirmam que aprenderam os conceitos básicos nas formações. No entanto, é importante considerar que os professores participaram de formações continuadas, incluindo a formação do ProJovem Campo. De fato, alguns complementaram suas respostas afirmando que tinham aprendido tais conceitos em outras situações como, por exemplo, em pesquisas que realizaram por esforço próprio.

A Tabela 8 é referente às respostas dos professores a seguinte questão: Você pode citar situações nas quais os estudantes do ProJovem Campo precisam utilizar conhecimentos de Estatística? Esta pergunta teve por objetivo identificar alguns conteúdos estatísticos que eventualmente estavam sendo trabalhados nas escolas com os jovens e adultos camponeses, em grande parte, agricultores e agricultoras familiares que precisavam planejar seus gastos e produções.

Tabela 8. Situações nas quais os jovens e adultos do Campo precisavam utilizar conhecimentos de Estatística: respostas dos educadores

\begin{tabular}{lc}
\hline \multicolumn{1}{c}{ Sínteses das respostas } & \multicolumn{1}{c}{$\begin{array}{c}\text { Número de } \\
\text { Educadores (\%) }\end{array}$} \\
\hline $\begin{array}{l}\text { Situações concretas do cotidiano ligadas às produções e/ou } \\
\text { à comercialização e/ou ao planejamento doméstico }\end{array}$ & $44(35 \%)$ \\
$\begin{array}{l}\text { Situações ligadas às pesquisas apresentadas na mídia } \\
\text { (exemplo: televisão, jornais e revistas) e na comunidade }\end{array}$ & $17(14 \%)$ \\
Interpretação e/ou construção de gráficos e tabelas & $12(10 \%)$
\end{tabular}


Fonte: Acervo da pesquisa.

Embora a maioria das respostas tenha sido genéricas, organizamo-las por professor e por situações citadas. Situações ligadas às produções e/ou à comercialização e/ou ao planejamento doméstico foram apontadas por 35\% dos professores. Situações mais pontuais, como as pesquisas apresentadas na mídia, foram ressaltadas por $14 \%$ dos professores. Esses resultados indicam que a maioria dos professores, de alguma maneira, reconhece a importância da Estatística para a vida das pessoas do Campo. Estão em consonância com a proposta pedagógica do ProJovem Campo que pressupõe o ensino dos conteúdos escolares de maneira integrada e contextualizada com a realidade e as práticas sociais. O ensino nesta perspectiva inclui o desenvolvimento da habilidade de interpretar gráficos e tabelas divulgados pela mídia nacional e local nas comunidades camponesas, contribuindo para uma participação ativa do cidadão na vida social e política do Campo.

Tendo em vista que no momento da coleta de dados os professores estavam participando da formação continuada do ProJovem Campo, fizemos o seguinte questionamento: A formação continuada do ProJovem Campo contribui para seu trabalho com Estatística em sala de aula? As respostas dos professores são apresentadas na Tabela 9.

Tabela 9. A formação continuada do ProJovem Campo contribui para seu trabalho com Estatística em sala de aula?

\begin{tabular}{lr}
\hline \multicolumn{1}{c}{ Respostas } & Número de Educadores (\%) \\
\hline Sim & $81(65 \%)$ \\
Não & $18(15 \%)$ \\
Não responderam & $25(20 \%)$ \\
\hline Total & $\mathbf{1 2 4}(\mathbf{1 0 0 \% )}$ \\
\hline
\end{tabular}

Fonte: Acervo da pesquisa.

A maioria dos respondentes $(65 \%)$ considerou que a formação continuada em andamento contribuía para o ensino de Estatística no contexto do Campo. Esse percentual de professores é maior do que os $56 \%$ que afirmaram ter aprendido os conceitos básicos para ensinar Estatística nas formações (Cf. Tabela 7). É possível que alguns professores não tenham incluído a formação em curso nas suas respostas anteriores, o que explicaria tal resultado.

Buscando acessar outros elementos de resposta sobre a contribuição da formação continuada do Programa, questionamos: Como a formação continuada do ProJovem Campo 
contribui para seu trabalho com Estatística em sala de aula? As respostas dos professores estão apresentadas na Tabela 10.

Tabela 10. Contribuições da formação continuada do ProJovem Campo no trabalho com Estatística em sala de aula

\begin{tabular}{lr}
\hline Respostas & Número de Educadores (\%) \\
\hline Na elaboração de planejamentos & $37(30 \%)$ \\
Nas trocas de experiências & $13(10 \%)$ \\
No trabalho com gráficos e tabelas & $10(08 \%)$ \\
Contribui, mas é insuficiente. & $06(05 \%)$ \\
$\begin{array}{l}\text { Não contribui porque a Estatística não foi } \\
\text { trabalhada no curso. }\end{array}$ & $05(04 \%)$ \\
Não contribui porque a Estatística foi pouco & \\
trabalhada no curso. & $06(05 \%)$ \\
Não responderam & $47(38 \%)$ \\
\hline Total & $\mathbf{1 2 4}(\mathbf{1 0 0 \% )}$ \\
\hline
\end{tabular}

Fonte: Acervo da pesquisa.

Considerando que o questionário foi aplicado quando os educadores estavam no terceiro módulo (tempo universidade) dos seis previstos, evidencia-se que para $48 \%$ deles a formação contribuía de alguma maneira com o trabalho que realizavam junto aos educandos. As explicações vão desde a elaboração dos planejamentos, passando pelo trabalho com gráficos e tabelas, até a troca de experiências que era realizada com outros professores em formação. Assim, eles destacaram a contribuição pedagógica da formação, para além dos conteúdos estatísticos. Nota-se que seis professores não identificaram qualquer contribuição do curso para o trabalho com a Estatística, e que um número relativamente elevado de professores (38\%) não responderam a questão. No entanto, os dados obtidos não nos fornecem os elementos necessários para compreender essas respostas.

Embora não tenhamos voltado a questionar os professores após o término do curso, consideramos que esses resultados dão indicativos importantes para o planejamento das formações continuadas no que se refere ao trabalho com a Estatística.

\section{Considerações finais}

As análises das respostas de 124 professores que participaram da pesquisa objetivaram a identificação do perfil de formação e profissional, bem como de alguns aspectos da formação inicial e continuada sobre o ensino de conteúdos estatísticos. Mesmo considerando que tais respostas fizeram parte de um estudo mais ampliado sobre a formação dos educadores que atuaram no 
Programa ProJovem Campo em Pernambuco, pode-se identificar diversos elementos que oferecem subsídios para discussões sobre a formação de professores que atuam nas Escolas do Campo.

Por exemplo, os resultados obtidos mostram que 75\% dos professores afirmaram ter estudado conteúdos estatísticos na formação inicial (graduação). Entretanto, desses apenas 35\% lembravam de alguns tópicos estatísticos que foram estudados e listaram corretamente tais conteúdos. Considerando a formação inicial dos professores e que tais conteúdos já haviam sido introduzidos na formação continuada que estavam cursando, esses resultados apontam para a necessidade de se investigar, de maneira mais aprofundada, o ensino de conteúdos estatísticos no âmbito da formação de professores.

Uma vez que os conteúdos estatísticos têm repercussão nas práticas sociais dos educandos camponeses, são necessários esforços para que a formação inicial e continuada dos professores possam incorporar os conhecimentos básicos dessa área, como também estratégias integradoras tais como aquelas defendidas no Programa ProJovem Campo.

Assim, em futuras pesquisas faz-se necessário explorar como os saberes vinculados aos conteúdos estatísticos que são construídos e mobilizados pelos professores se relacionam com o ensino nas escolas do Campo. Essa temática constitui-se em um desafio importante para a efetivação de um ensino de Matemática que possa contribuir para o exercício pleno da cidadania por educadores e educandos do Campo.

\section{Referências}

ALCÂNTARA, L. R. O ensino de conteúdos estatísticos no ProJovem Campo - Saberes da Terra em Pernambuco. 2012. Dissertação (Mestrado em Educação Matemática e Tecnológica) Programa de Pós-Graduação em Educação Matemática e Tecnológica, Universidade Federal de Pernambuco, Recife, 2012.

BRASIL. Projeto base ProJovem Campo - Saberes da Terra. Secretaria de Educação continuada, alfabetização e diversidade Secretaria de Educação profissional e tecnológica do Ministério da Educação. Brasília: SECAD/MEC, 2008a.

BRASIL. Coleção cadernos pedagógicos do ProJovem Campo-Saberes da Terra. Percurso formativo. Secretaria de Educação Continuada, Alfabetização e Diversidade do Ministério da Educação. Brasília: SECAD/MEC, 2008b.

BRASIL. Parâmetros curriculares nacionais: Matemática. Brasília: Ministério da Educação e Desporto - Secretaria do Ensino Fundamental, 1997.

CALDART, R. S. Educação do Campo. In CALDART et al. (Org.). Dicionário da Educação do Campo. Rio de Janeiro, São Paulo: Escola Politécnica de Saúde Joaquim Venâncio, Expressão Popular, 2012. 
CARVALHO, C.; SOLOMON, Y. Supporting statistical literacy: What do culturally relevant/realistic tasks show us about the nature of pupil engagement with statistics? International Journal of Educational Research, v. 55, p. 57-65, 2012.

FARIAS, M. O acompanhamento pedagógico e o ensino de matemática em escolas rurais: analisando concepções e práticas. 2010. 173 f. Dissertação (Mestrado em Educação Matemática e Tecnológica) - Programa de Pós-Graduação em Educação Matemática e Tecnológica, Universidade Federal de Pernambuco, Recife, 2010.

FREIRE, P. Pedagogia da Autonomia: saberes necessários à pratica educativa. São Paulo: Paz e Terra, 1996 (Coleção Leitura).

GIMONET, J. C. Praticar e compreender a Pedagogia da Alternância dos CEFFAs. Petrópolis: Vozes, Paris: AIMFR, 2007.

INAF. Indicador de Analfabetismo Funcional 2011-2012. São Paulo: Instituto Paulo Montenegro, Ação Educativa, 2012. Disponível em:

http://www.ipm.org.br/ipmb_pagina.php?mpg=4.02.01.00.00\&ver=por. Acesso em: jul. 2014.

KNIJNIK, G.; WANDERER, F. Programa Escola Ativa, escolas multisseriadas do campo e educação matemática. Educação e Pesquisa, São Paulo, v. 39, n. 1, p. 211-225, jan./mar. 2013. Disponível em: <http://www.scielo.br/pdf/ep/v39n1/v39n1a14.pdf>. Acesso em: 08 jul. 2014.

LIMA, A. S. Educação do Campo e Educação Matemática: relações estabelecidas por camponeses e professores do Agreste e Sertão de Pernambuco. Dissertação (Mestrado em Educação Contemporânea. Caruaru: Centro Acadêmico do Agreste da Universidade Federal de Pernambuco, 2014.

LIMA, I. M. S.; Franco, M. J. N. Um olhar sobre a formação continuada de educadores/as do Programa ProJovem Campo Saberes da Terra em Pernambuco. In: LIMA, I. M. S.; FRANCO, M. J. N.; CUNHA, K. S. (Org.). Reflexões e ações sobre Educação, Estado e Diversidade. 2. ed. Recife: EDUFPE, v. 4. 2014 (Coleção Educação, Saberes e Práticas Didático-Pedagógicas).

MONTEIRO, C. E. F.; SILVA, V. L.; ASSEKER, A. Ensinando Matemática em contextos sócioculturais de Educação do Campo. Horizontes (EDUSF), v. 27, p. 69-78, 2009.

MUNARIM, A. Educação do campo: desafios teóricos e práticos. In: MUNARIM, A.; BELTRAME, S.; CODE, S. F.; PEIXER, Z. I. (Org.). Educação do campo: reflexões e perspectivas. 2. ed. Florianópolis: Insular, 2011.

SANTOS, S. S.; MAGINA, S. M. P. Estratégias de interpretação gráfica de uma professora polivalente ao manipular dados no ambiente computacional. Bolema, Rio Claro, ano 21, n 29, p 157-174, dez 2007. Disponível em: < http://www.rc.unesp.br/igce/matematica/bolema/>. Acesso em: 05 de mai. 2010.

SKOVSMOSE, O. Desafios da reflexão em educação matemática crítica. Tradução de Orlando de Andrade Figueiredo, Jonei Cerqueira Barbosa. São Paulo: Papirus, 2008 (Coleção Perspectivas em Educação Matemática). 
. Educação matemática crítica: a questão da democracia. Campinas-SP: Papirus, 2001 (Coleção Perspectivas em Educação Matemática). (Impresso), v. 11. Belo Horizonte: RBLA, p. 135-148.

WANDERLEY, M. N. A ruralidade no Brasil moderno. Por un pacto social pelo desenvolvimento rural. In: GIARRACCA, Norma. ¿Una nueva ruralidad en América Latina? Buenos Aires:

CLACSO, Consejo Latinoamericano de Ciencias Sociales, 2001.

Submetido em julho de 2014 Aprovado em dezembro de 2014 